\title{
A BNCC E O COMPONENTE CURRICULAR DE LÍNGUA INGLESA: ALGUMAS REFLEXÓES
}

\author{
Carla Pereira de Oliveira ${ }^{1}$
}

\begin{abstract}
Resumo: Este trabalho buscar refletir sobre o Componente Curricular Língua Inglesa para o ensino e aprendizagem na perspectiva da proposta da Base Nacional Comum Currricular (BNCC) para o ensino fundamental. Para tanto, pauta-se em estudos documentais e bibliográficos pretendendo verificar as perspectivas desse documento para o processo de ensino e aprendizagem desse componente curricular. Resultados dessa análise indicam para possíveis conflitos e desencontros nos pressupostos pedagógicos indicados pela BNCC, quanto ao uso do conceito língua franca, tanto na composição dos quadros que contemplam os objetivos, conteúdos e as habilidades de aprendizagem apresentados pela BNCC quanto ao que se refere à padronização de conteúdos e a ênfase dada ao ensino estrutural da língua, trazendo assim implicaçóes para o ensino de qualidade de uma língua que é falada mundialmente por indivíduos de diferentes nacionalidades.
\end{abstract}

Palavras-chave: BNCC; língua inglesa; língua franca; ensino; aprendizagem.

\section{BNCC AND THE ENGLISH LANGUAGE CURRICULUM COMPONENT: SOME REFLECTIONS}

\begin{abstract}
This work seeks to reflect on the English Language Curriculum Component for teaching and learning in the perspective of the proposal of the Common National Curriculum Base (BNCC) for elementary education. Therefore, it is based on documentary and bibliographic studies, intending to verify the perspectives of this document for the teaching and learning process of this curricular component. Results of this analysis point to possible conflicts and mismatches in the pedagogical assumptions indicated by the BNCC, regarding the use of the lingua franca concept, both in the composition of the tables that include the objectives, contents and learning skills presented by BNCC as well as with regard to standardization of contents and the emphasis given to the structural teaching of the language, thus bringing implications for the quality teaching of a language that is spoken worldwide by individuals of different nationalities.
\end{abstract}

Keywords: BNCC; English language; lingua franca; teaching; learning.

1 Doutoranda pela Universidade Federal de Uberlândia - UFU. E-mail: prof.carlapo@gmail.com. 


\section{Introduçáo}

Neste artigo, exponho e discuto a Base Nacional Comum Curricular no âmbito do Componente Curricular Língua Inglesa e alguns conceitos como a Língua Inglesa (LI) com o status de língua franca (ILF), que foi implementado no documento para o ensino de Língua Inglesa (LI). Primeiramente, apresento uma breve contextualização do documento, conceituando a BNCC e discorrendo sobre os objetivos, o planejamento, a elaboração e a implementação desse documento em nosso país. Logo em seguida, exponho a estruturação do documento e finalmente analiso o Componente Curricular Língua Inglesa e a implementação do inglês como língua franca (ILF), e de que modo essa proposta do documento está se realizando na sala de aula de Língua Inglesa (LI). Para tanto, me apoio em trabalhos de pesquisadores da Linguística Aplicada (DUBOC, 2019; RAJAGOPALAN, 2019, RIBAS, 2018; SZUNDY, 2019; TILIO, 2019), que revelam contradições e/ ou descompassos acerca dos pressupostos teóricos que constroem o texto da BNCC.

Para realização desse estudo utilizou-se a pesquisa documental e bibliográfica (Gil, 2002), sendo analisados o documento oficial da BNCC e materiais relacionados à temática.

\section{BNCC: Uma breve contextualizaçáo}

Atualmente, temos no Brasil, um documento oficial que tem a função de regulamentar as políticas educacionais para a Educação Infantil, Ensino Fundamental e Ensino Médio, orientando as diretrizes gerais e específicas para cada componente curricular, e os objetivos a serem alcançados em cada etapa de ensino que é a Base Nacional Curricular - BNCC.

A Base Nacional Comum Curricular (BNCC) é um documento de caráter normativo que define o conjunto orgânico e progressivo de aprendizagens essenciais que todos os alunos devem desenvolver ao longo das etapas e modalidades da Educaçáo Básica, de modo que a tenham assegurados seus direitos de aprendizagens e desenvolvimento, em conformidade com o que preceitua o Plano Nacional de Educação. (PNE) (BRASIL, 2017, p. 5)

A BNCC foi planejada desde a promulgação da Lei de diretrizes e Bases da Educação de 1996. Em junho de 2015, foram definidos os profissionais qualificados para fazerem parte da comissão de especialistas para a elaboração da proposta da Base Nacional Comum Curricular. Foi escrita e homologada dentro de aproximadamente 4 anos passando por 2 versôes com espaço para contribuiçôes e para melhorias. A terceira versão da BNCC foi homologada em 20 de dezembro de 2017. O CNE, em 22 de dezembro de 2017 apresenta a resolução CNE/CP No 2 para a implementaçáo da BNCC em todo território nacional. Desde entáo os professores e todos os profissionais da educação se dedicaram a compreender sua implementação e os possíveis impactos na educação do Brasil. 
O Brasil já teve outros documentos orientadores como os $\mathrm{PCN}^{2}$ e as $\mathrm{OCEM}^{3}$, mas o grande diferencial é que a BNCC é Lei, sendo assim obrigatória. O documento é um conjunto de referenciais para serem utilizados na elaboração dos currículos dos estados brasileiros, portanto, é um currículo mínimo, porque todo o seu conteúdo é obrigatório e tem que ser incluído nos currículos estaduais. Um currículo único para todo o território nacional, uma educação igualitária para todos os brasileiros, sem o olhar das diversidades e necessidades das diversas realidades do nosso país. Segundo Tilio (2019),

Pois é isso que a BNCC faz, tentando passar a ideia de que basta haver um currículo nacional único para que aprendizagem seja supostamente homogeneizada em todo o país, independentemente das especificidades e dificuldades de cada regiáo, de cada contexto e de cada instituição. (TILIO, 2019, p. 12)

O objetivo da implementação da BNCC parece ser de oportunizar uma mesma educaçáo a todos os brasileiros, em todas as regióes do país e em qualquer escola em que estivesse estudando, sem levar em conta a dimensão do nosso país, a diversidade e peculiaridades da população brasileira. O que fica claro com a implementação da BNCC é que "todos têm chances iguais, e aqueles que não foram bem-sucedidos não o foram por (falta de) mérito próprio" (TILIO, 2019, p. 12).

Embora a BNCC traga um discurso teórico favorável para resolver os problemas da educação e das políticas educacionais no âmbito nacional, a homologação dela trouxe grande desconforto aos pesquisadores da área, especialistas em educação e em Linguistas Aplicados (LA) que apontaram contradições no discurso teórico que realmente a base propóe. Ribas (2018) advoga que

Alguns pontos de vista contrários à base referem-se ao náo respeito à diversidade e aos conhecimentos locais dos aprendizes, e também ao fim da autonomia docente. A padronização de conteúdos a serem trabalhados pelos professores acabaria indicando aos alunos que há formas corretas e legítimas de pensar e de se expressar que compóem uma cultura elitista dominante, o que causaria efeito de exclusão e marginalização de alguns grupos. As diferenças existentes no país seriam, então reforçadas. (RIBAS, 2018, p. 1786)

Rajagopalan (2019) corrobora com Ribas (2018) sobre a problemática trazida pela homogeneização de conteúdos, ao afirmar que

Quando se propóe um mesmo remédio para um universo tão diverso, estamos de fato imaginando um sujeito ideal como receptor do tratamento. Acontece que os sujeitos reais espalhados pelo vasto território nacional têm, cada um a seu modo, necessidades e carências que lhe são próprias. Na verdade, como os defensores de currículo unificado imaginam, que as necessidades e carências específicas dos aprendizes, bem como suas expectativas e aspiraçóes, possam ser

2 PCN - Parâmetros Curriculares Nacionais.

3 OCEM - Orientações Curriculares para o Ensino Médio. 
atingidas da mesma maneira - possibilidade essa fadada a conduzir à frustação inevitável e ao eventual desencanto. (RAJAGOPALAN, 2019, p. 29).

Portanto, entende-se que um currículo com conteúdos padronizados, sem respeitar a diversidade, a cultura, o contexto social e sem aspirar as verdadeiras necessidades de contextos táo diversificados quanto as do povo brasileiro, possui grandes possibilidades de se concretizar nas escolas como um grande insucesso. Um currículo construído para atender um aluno supostamente ideal? Ideal para quê? Para quem?

Um currículo único, como propóe a base, seria a garantiria que os alunos aprenderiam os mesmos conteúdos, e que resolveria o problema das desigualdades, pois estaria oportunizando o mesmo direito à aprendizagem a todos. Mas diante da diversidade de nosso pais, as peculiaridades regionais, as especificidades culturais e a heterogeneidade dos contextos escolares, um currículo único parece estar fadado ao fracasso e as desigualdades e diferenças sociais poderiam ser ainda mais reforçadas, segundo Gerhardt e Amorim (2019)

[...] um ensino bem-sucedido é aquele que se dá na prática, e o que importa não é o conteúdo a ser repassado, mas sim a relação do professor com a realidade de sala de aula, e a relaçáo do aprendiz com o professor e com a própria aprendizagem. (GERHARDT; AMORIM, 2019, p. 20).

Um currículo de sucesso deve considerar a sua realidade local, dando autonomia ao professor para que respeite seu contexto escolar e atenda as vivências e necessidades que os alunos apresentam, respeitando a ampla diversidade geográfica, social e cultural do nosso país, não só conteúdos padronizados, mas sim, ser responsivo às realidades locais, sem minar a autonomia das escolas e dos professores, o currículo deve acontecer no chão da sala de aula.

\section{Organizaçáo estrutural da BNCC}

A BNCC foi elaborada com o objetivo de se ter clareza em sua estrutura. Está dividida de modo a apresentar as competências gerais que os alunos deverão desenvolver ao longo de suas etapas de escolaridade com o objetivo de um ensino que "está orientado pelos princípios éticos, políticos e estéticos que visam à formação humana integral e à construção de uma sociedade justa, democrática" (BRASIL, 2018, p. 7). Essas competências gerais estabelecem para as quatro áreas do conhecimento "competências específicas de área. Essas competências explicitam como as dez competências gerais se expressam nessas áreas" (p. 28). As competências específicas, associadas às competências gerais visam "garantir o desenvolvimento das competências específicas" e "cada componente curricular apresenta um conjunto de habilidades. Essas habilidades estão relacionadas a diferentes objetos de conhecimento - aqui entendidos como conteúdos, conceitos e processos" (p. 28). As habilidades corresponderiam às capacidades que os estudantes iriam adquirir, como desdobramentos das competências específicas para cada componente curricular. 
Os componentes curriculares estáo organizados em quatro grandes áreas do conhecimento: Linguagens, Matemática, Ciências da Natureza e Ciências Humanas, que se desdobram nos componentes curriculares: Língua Portuguesa, Arte, Educação Física, Língua Estrangeira Moderna/Língua Inglesa, Matemática, Ciências, História e Geografia. Eles estão também organizados em unidades temáticas para que se possam relacionar as habilidades (objetivos de aprendizagem) aos seus respectivos objetos de conhecimento.

A BNCC, ao organizar o currículo mínimo em áreas de conhecimento, incentiva um trabalho interdisciplinar, prevendo a interlocuçáo entre os diversos componentes curriculares. De acordo com a BNCC:

Decidir sobre formas de organização interdisciplinar dos componentes
curriculares e fortalecer a competência pedagógica das equipes escolares para
adotar estratégias mais dinâmicas, interativas e colaborativas em relação à
gestáo do ensino e da aprendizagem. (BRASIL, 2017, p. 12)

Segundo o documento, a interdisciplinaridade é um dos caminhos para superar a fragmentação dos conteúdos e dos currículos escolares. Entendo ser de extrema importância essa articulação interdisciplinar que direcione para uma proposta integradora nos conteúdos e objetivos de aprendizagem, contudo, a BNCC, em se tratando da área de Língua Inglesa (LI), não favorece a interdisciplinaridade, primeiramente porque apresenta-se uma proposta em eixos, mas da forma com que foram dispostos no documento, os eixos são tratados separadamente, ou seja, não há conexão entre eles; em segundo lugar, por trazer os conteúdos fragmentados em habilidades, o que dificulta a articulaçáo do ensino nas práticas sociais do uso da Língua Inglesa (LI), desarticulando as situaçóes de aprendizagens no planejamento das aulas pelo professor. A organização dos conteúdos em eixos "sugere um retorno às abordagens cognitivistas e estruturalistas que caracterizaram o ensino de línguas nas décadas de 1970 e 1980" (SZUNDY, 2019, p. 142).

\section{A BNCC e o Componente Curricular Língua Inglesa}

O Componente Curricular Língua Inglesa é apresentado com enfoque para um ensino/ aprendizagem voltado para a globalização, que possibilitará ao aluno o acesso aos saberes linguísticos necessários para seu desenvolvimento crítico e valorizando a língua com sua função social e política. De acordo com o documento "ensinar inglês com essa finalidade tem, para o currículo, três implicaçóes" (BRASIL, 2018, p. 241), sendo elas, "a língua com um caráter formativo (educação linguística), de multiletramentos (práticas sociais do mundo digital...participação e circulação em diferentes "semioses e linguagens (verbal, visual, corporal, audiovisual)" (BRASIL, 2018 , p. 240) e a abordagem do ensino que situa "a língua inglesa em seu status de língua franca [...]. Isso exige do professor uma atitude de acolhimento e legitimação de diferentes formas de expressão na língua [...]" (BRASIL, 2018, p. 240).

Segundo o documento, o professor deve oportunizar ao aluno refletir "observando sempre a condição de inteligibilidade na interação linguística" (BRASIL, 2018, p. 240), "buscando romper com aspectos relativos à 'correção', 
'precisão' e 'proficiência' linguística" (BRASIL, 2018, p. 240). De acordo Szundy (2019), um primeiro olhar nessas afirmaçóes constantes na BNCC nos leva a acreditar que o documento insere uma perspectiva decolonial ${ }^{4}$ no ensino de inglês "ao defender a não prerrogativa de falantes nativos sobre os muitos usos do que chamamos de inglês e a legitimidade desses usos por todos/as aqueles/as que o utilizam" (SZUNDY, 2019, p. 144).

$\mathrm{Na}$ Base Nacional Comum Curricular ficou definida a Língua Inglesa (LI) como Língua Estrangeira (LE) obrigatória que deverá ser ensinada no Ensino Fundamental II em todas as escolas brasileiras públicas ou privadas, desde o ensino fundamental ( $6^{\circ}$ ano) ao médio. Com a aprovação da medida provisória 746/2016 trouxe também concepção da língua franca (ILF) reconhecido pela Língua Inglesa (LI) "[...] compreende-se desta forma, estar sendo reconhecido na legislação o caráter de língua franca de comunicação internacional assumido pela língua inglesa, bem como bem como seu papel central na mediação de práticas interculturais" (COUTINHO, 2017, p. 3). Conceber a língua franca (ILF) no ensino da Língua Inglesa (LI) permite que se ensine diferentes repertórios linguísticos, sem se nortear por apenas um único inglês correto, e permite um ensino voltado para a interculturalidade, com reconhecimento e respeito à diversidade e diferenças culturais.

Mas, de acordo com Duboc (2019), o "conceito de ILF caiu praticamente de paraquedas no Componente Curricular Língua Inglesa da BNCC (BRASIL, 2017) e tendo em vista que é praticamente nula a discussão sobre o conceito de ILF na formação docente inicial e continuada" (GIMENEZ, EL KADRI, CALVO, 2018; COGO, SIQUEIRA, 2017), com o advento da globalização e o ampliaçáo da expansão da língua inglesa mundialmente, como consequências de fatores socioculturais, políticos e econômicos, seria necessário primeiramente que os professores se engajassem em formaçôes para a reflexão sobre o uso da língua franca (ILF). Gimenez (2014, p. 13) corrobora pontuando que:

Observa-se uma carência de reflexôes sob uma perspectiva de autores
brasileiros que reflitam o olhar de usuários e aprendizes em contexto do
"Círculo de Expansão" a respeito da língua franca global. Dado que o assunto
é relativamente novo, faz-se necessária uma revisão sistemática da literatura
que englobe as pesquisas realizadas no contexto brasileiro, a fim de identificar
os temas por elas tratados, os contextos de pesquisas e suas implicaçôes.
(GIMENEZ, 2014, p. 13)

Sendo assim, para que essa mudança na concepção de língua realmente aconteça na sala de aula, de sistema fechado à prática social e à língua franca (ILF), prevalece a grande necessidade de estudos, trabalhos e publicaçóes na perspectiva de língua franca (ILF), a fim de subsidiar os professores a assumir em suas aulas essa

4 Segundo Mignolo (2007), a perspectiva decolonial pressupóe enfrentamento aos padróes eurocêntricos, buscando por outras formas de compreensão de si, organização social e construção do conhecimento. 
nova modalidade de língua franca (ILF), ao invés do inglês padráo que costuma ser vigente nas aulas de Língua Inglesa (LI). Duboc (2019) advoga que

O ensino de inglês no Brasil é marcado historicamente por um discurso de fracasso já denunciado por pesquisadores brasileiros [...]. Um dos fatores relacionados a esse discurso se refere ao ranço colonialista do inglês e a empreitada árdua de muitos brasileiros na busca idealizada do "domínio" do idioma, calcado em preceitos como precisão, pureza e imitaçáo do falante nativo. (DUBOC, 2019, p.16)

A Língua Inglesa (LI) sempre foi considerada uma disciplina menos importante, que pouco contribui para a formação dos alunos do mesmo modo que as matérias do núcleo comum, como o português e a matemática, esse componente curricular sempre carregou um descrédito dentro do currículo comum, e não foi diferente na elaboração da BNCC que suas diretrizes não conseguiram mudar esse quadro negativo. Segundo Duboc (2019)

Se de um lado as consideraçóes tecidas no texto introdutório coadunam-se com conceitos e categorias pertinentes para o repensar do status do inglês na contemporaneidade, de outro, a análise dos quadros didáticos dispostos ano a ano evidenciam, paradoxalmente, lapsos de engessamento de conteúdos, ecoando - ainda que o documento se coloque afeito a um desenho curricular espiralado - um discurso atualizado que camufla conteúdos de língua tradicionalmente ensinados numa lógica de linearidade e hierarquização (Simple Present no $6^{\circ}$ ano > Simple Past no $7^{\circ}$ ano $>$ Future Forms no $8^{\circ}$ ano). Eis o conflito epistemológico: como pode um documento acolher os usos criativos, híbridos e locais do inglês em seu status de língua franca se o próprio documento organiza, linear e hierarquicamente, temas, objetos de conhecimento e habilidades, com exemplos de conteúdos linguísticos fixos e estáveis? (DUBOC, 2019, p. 18)

Duboc (2019) apoiando-se em Cogo e Siqueira (2017), afirma que o ILF, quando pensado em contextos educacionais, refuta qualquer pretensão de se impor o que deve e o que não deve ser ensinado na aula de inglês (COGO E SIQUEIRA, 2017), corroborando Jordão e Marques (2018) asseguram que, sob a perspectiva do ILF, deve-se mudar o foco em regras gramaticais institucionalizadas para o encorajamento da negociação entre as diversas gramáticas e repertórios linguísticoculturais que emergem das situaçôes comunicativas em inglês, sendo assim não se pode conceber um ensino de ILF baseado em conteúdos gramaticais impostos, em um currículo engessado, de que forma os alunos terão então acesso a uma nova língua ILF, a uma outra cultura, ao respeito às diversidades socioeconômicas se o próprio currículo propõe na teoria mas não oportuniza essa concretização na prática das aulas de inglês.

De acordo com Szundy (2019), a ideologia de língua franca (ILF) assumida pela BNCC permitiria o ensino e aprendizagem de inglês como "um espaço de contestaçáo, de reivindicação dos direitos da periferia, de subversáo, e não da submissão" (RAJAGOPALAN, 2005, p. 155), portanto de acordo com a autora "esse olhar mais esperançoso [...] logo se desfaz quando nos deparamos com as habilidades estipuladas para o componente, que parecem privilegiar a visão 
de texto(s) como unidade(s) autônomas, e uma dimensáo intercultural pouco problematizadora." (SZUNDY, 2019, p. 144)

As habilidades de leitura para o parecem se ancorar na ideologia linguística de que os textos constituem unidades de sentido autônomas cujos significados podem ser depreendidos a partir da utilização de estratégias de leitura e aquisiçáo de vocabulário. As concepçóes de que os textos representam a realidade e de que essa representação pode ser apreendida através da localização de informações são entextualizadas em habilidades como formular hipóteses sobre a finalidade de um texto em lingua inglesa, com base em sua estrutura, organizaçâo textual e pistas gráficas (EF06LI07), identificar o assunto de um texto, reconhecendo sua organização textual e palavras cognatas (EF06LI08) e localizar informaçóes especificas do texto (EF06LI09). A utilização dos verbos formular, identificar, e localizar nessas três habilidades de leitura contraria o caráter formativo e político da língua inglesa defendido na apresentação do componente e a perspectiva de língua franca privilegiada pelo documento: esses enquadres ideológicos orientam-se por uma visão de textos (verbais el ou não verbais) como recursos semióticos que (des/re)constroem realidades sempre forjadas em trajetórias textuais através de processos contínuos de des/ recontextualização. (SZUNDY, 2019, p. 144)

Ainda sobre a perspectiva do ensino e aprendizagem de língua franca (IFL) que a BNCC direciona, a autora advoga que

o status do inglês como língua franca na BNCC parece, portanto, estar a serviço do neoliberalismo - atende ao desenvolvimento de competências e habilidades para que o/a aluno/a se torne um/a empreendedor/a de si mesmo/a, de forma a habilitá-lo/a participar desse mundo global sem questionar suas macros e micros estruturas, e como estas operam para manter um grande contingente de população mundial sem acesso às commodities dessa utópica aldeia globa $\overline{\text {. }}$. (SZUNDY, 2019, p. 146-147)

Sendo assim, a BNCC se distancia do ILF, não garante a convergência das habilidades, competências específicas desse componente curricular com o que propóe o texto introdutório, se afasta de um ensino consciente e crítico que está diretamente ligado ao caráter formativo e político, que direciona um trabalho com a diversidade linguística, que busca as interaçóes como prática social, capaz de formar cidadãos engajados na sociedade em que vivem e serem protagonistas da sua realidade. Rajagopalan (2019, p. 26) advoga que "o ensino bem-sucedido se dá na prática" e ainda enfatiza que "o que vale é como o conteúdo é trabalhado na sala de aula". Portanto, ficará a cargo dos professores a(s) maneira(s) como esse currículo, com tantos desencontros e descompassos, se concretizará no "chão da sala de aula". Para o autor, "importante mesmo é saber até que ponto o professor está atento à realidade em que se encontra o aprendiz e até que ponto ele está sensível aos anseios, as aspiraçôes e as angústias de quem está no lado receptor do esforço do esforço pedagógico" (RAJAGOPALAN, 2019, p. 26). Será que o professor está

5 Aldeia global FIGUEIREDO (2018). 
preparado para esse desafio? Como está a realização de documento tão cheio de contradiçôes e descompassos na sala de aula?

\section{Consideraçóes Finais}

A Base Nacional Comum Curricular (BNCC) embora pareça trazer um discurso de inovação e ideias revolucionárias, o que realmente se percebe é uma orientação para um ensino e aprendizagem que não valoriza a formação crítica do cidadão priorizando a formaçáo para o marcado de trabalho cumprindo um papel a favor do neoliberalismo. É um documento falho quanto a orientaçáo para o ensino da língua franca (ILF) pois notamos um desencontro do texto introdutório com o que realmente se encontra nas habilidades, conteúdos e objetivos, afastando-se de um ensino crítico, com a valorização da diversidade com ênfase nas práticas sociais e um caráter formativo de cidadáos críticos capazes de envolver-se em lutas por uma sociedade mais justa e igualitária.

Compreende-se que para uma verdadeira mudança no ensino de inglês, direcionado principalmente para o status da língua franca (ILF), seria necessário principalmente uma conscientizaçáo dos professores para realmente trabalhar em sala de aula a diversidade linguística da Língua Inglesa (LI), através das práticas sociais sem enfatizar um modelo padrão da língua, portanto torna-se necessário uma efetiva formação dos professores. De acordo com Siqueira e Anjos (2012 apud Bordoni; Gimenez, 2014, p. 30), é fundamental que "[...] um investimento maciço na formação inicial/continuada de professores precisa ser realizada para que a escola pública seja palco de mudanças", para transpor esses conflitos e limitaçóes impostos pelas propostas do documento e vislumbrar verdadeiramente uma transformação na sala de aula de Língua Inglesa (LI) e, de acordo com Szundy (2019, p. 148), "só assim poderemos esperançar, verbo que segundo Freire (1992) demanda inter(ação) conjunta, e não espera, que a educação construa futuros mais equânimes e éticos, orientados pela coexistência pacífica de mundos e corpos distintos, e bem estar de muitos.”

\section{Referências}

BORDONI, M,; GIMENEZ, T. Estudos sobre Inglês como Língua Franca no Brasil (2005-2012): uma metassíntese qualitativa. Rev. SIGNUM: Estudos Linguísticos, Londrina, PR, v. 1, n. 17, p. 10-43, jun. 2014.

BRASIL. Base Nacional Comum Curricular. Brasília: Ministério da Educação/Secretaria da Educação Básica, 2017.

COGO, A.; SIQUEIRA, S. Emancipating myself, the students and the language: Brazilian teachers' attitudes towards ELF and the diversity of English Englishes. Practice. v. 4, n. 3, p. 50-78, 2017.

DUBOC, A. P. M. Falando Francamente: uma leitura bakhtiniana... In: Revista da Anpoll v. 1, no 48, p. 10-22, Florianópolis, Jan./Jun.2019. 
FAZENDA, I. C. Integraçáo e interdisciplinaridade no ensino brasileiro: efetividade ou ideologia. São Paulo: Loyola, 1979.

GERHARDT, A. F. L. M; AMORIM, M. A. A BNCC e o ensino de línguas e literaturas. (Orgs.) Campinas, SP : Pontes Editores, 2019.

GIL, A. C. Como elaborar projetos de pesquisa. 4. ed. São Paulo: Atlas, 2002.

GIMENEZ, M. S. EL KADRI, L. C. S. CALVO. (Org.). English as a lingua franca in teacher education: a Brazilian perspective. Berlin/Boston: De Gruyter, 2018.

GIMENEZ, T. et al. Inglês como língua franca: desenvolvimentos recentes. Rev. RBLA. Belo Horizonte, MG, V. 15, n. 3, p. 539-619, 2015.

JORDÁO. C. M. MARQUES, A. N. "English as a Lingua Franca and critical literacy in teacher Education: Shaking off some 'good old' habits". In: T. GIMENEZ, M. S. EL KADRI, L. C. S. CALVO. (Org.). English as a lingua franca in teacher education: a brazilian perspective. Berlin/Boston: De Gruyter, 2018, v. 10, p. 53-68.

RAJAGOPALAN, K. “A geopolítica da língua inglesa e seus reflexos no Brasil”. In LACOSTE, Y; RAJAGOPALAN, K. (eds.) A geopolítica do Inglês. São Paulo: Parábola Editorial, 2005, p. 135-158.

RAJAGOPALAN, K. Reforma Curricular e Ensino. In: GERHARDT, A. F. L. M.; AMORIM, M. A. (Orgs.) A BNCC e o ensino de línguas e literaturas. Campinas, SP: Pontes, p. 23-39, 2019.

RIBAS, F. C. Base Nacional Comum Curricular e o ensino de língua inglesa: refletindo sobre cidadania, diversidade e criticidade à luz do Letramento Crítico. In: Domínios de Lingu@gem, vol. 12, n. 3, p. 1785-1824 Uberlândia, jul - set. 2018.

SZUNDY, P. T. C. A Base Nacional Comum Curricular e a Lógica Neoliberal: Que Línguas(gens) são (Des)legitimadas? . In: GERHARDT, A. F. L. M; AMORIM, M. A. (Orgs.) A BNCC e o ensino de línguas e literaturas. Campinas, SP : Pontes Editores, 2019, p. 121-151.

TÍLIO, R. A Base Nacional Comum Curricular e o Contexto Brasileiro. In: GERHARDT, A. F. L. M; AMORIM, M. A. (Orgs.) A BNCC e o ensino de línguas e literaturas. Campinas, SP : Pontes Editores, 2019, p. 7-15. 